\title{
Papillary thyroid carcinoma with tall cell features is as aggressive as tall cell variant: a meta-analysis
}

\author{
Huy Gia Vuong ${ }^{1}$, Nguyen Phuoc Long ${ }^{2}$, Nguyen Hoang Anh ${ }^{3}$, Tran Diem Nghi ${ }^{3}$, Mai Van Hieu ${ }^{3}$, Le Phi Hung ${ }^{2}$, \\ Tadao Nakazawa', Ryohei Katoh ${ }^{1}$ and Tetsuo Kondo ${ }^{1}$
}

'Department of Pathology, University of Yamanashi, Yamanashi, Japan

${ }^{2}$ Faculty of Medicine, University of Medicine and Pharmacy at Ho Chi Minh City, Ho Chi Minh City, Viet Nam

${ }^{3}$ School of Medicine, Viet Nam National University, Ho Chi Minh City, Viet Nam

Correspondence should be addressed to T Kondo: ktetsuo@yamanashi.ac.jp

\begin{abstract}
There are still ongoing debates as to which cut-off percentage of tall cell (TC) should be used to define tall cell variant (TCV) papillary thyroid carcinoma (PTC). In this metaanalysis, we aimed to investigate the clinicopathological significance of PTC with tall cell features (PTC-TCF, PTC with $10-50 \%$ of TCs) in comparison with classical PTC and TCVPTC (PTC with more than $50 \%$ of TCs) to clarify the controversial issue. Four electronic databases including PubMed, Web of Science, Scopus and Virtual Health Library were accessed to search for relevant articles. We extracted data from published studies and pooled into odds ratio (OR) and its corresponding $95 \%$ confidence intervals (Cls) using random-effect modeling. Nine studies comprising 403 TCVPTCs, 325 PTC-TCFs and 3552 classical PTCs were included for meta-analyses. Overall, the clinicopathological profiles of PTC-TCF including multifocality, extrathyroidal extension, lymph node metastasis, distant metastasis and patient mortality were not statistically different from those of TCVPTC. Additionally, PTC-TCF and TCVPTC were both associated with an increased risk for aggressive clinical courses as compared to classical PTC. The prevalence of BRAF mutation in PTC-TCF and TCVPTC was comparable and both were significantly higher than that in classical PTC. The present meta-analysis demonstrated that even a PTC comprising only $10 \%$ of TCs might be associated with a poor clinical outcome. Therefore, the proportions of PTC in PTC should be carefully estimated and reported even when the TC component is as little as $10 \%$.
\end{abstract}

Key Words
- papillary thyroid
carcinoma
- tall cell feature
- tall cell
- meta-analysis
- review
- BRAF
- TERT
- prognosis
- survival
- aggressive

\section{Introduction}

Thyroid cancer is the most common endocrine cancer, and its incidence has been steadily increasing over the last few decades (1). There are several subtypes of thyroid carcinoma: papillary, follicular, poorly differentiated, undifferentiated and medullary carcinoma (2). Papillary thyroid carcinoma (PTC) is the most common subtype, which comprises more than $85 \%$ of thyroid cancers. Morphologically, PTCs are subdivided into variants, of which tall cell variant (TCV) is recognized as aggressive and associated with a poor prognosis (2).

Criteria for TCVPTC was first proposed in 1976 by Hawk and Hazard (3). In the previous WHO 2004 classification, however, the morphological criterion for the diagnosis of TCVPTC was vague: 'The TCV is composed predominantly of cells whose heights are at least three times their width' (4). In the latest WHO 2017
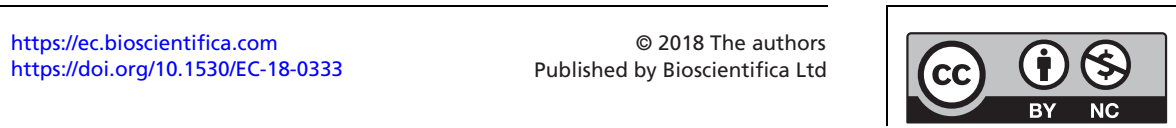

This work is licensed under a Creative Commons Attribution-NonCommercial 4.0 International License. 
classification, tall cells (TCs) were modified as tumor cells that are two to three times taller than wide. These cells were required to be present in at least $30 \%$ of all tumors cells to fulfill the diagnosis of TCVPTC (2).

However, there are still ongoing debates with regard to the percentage of TCs in a tumor required for the diagnosis of TCVPTC $(5,6,7,8)$. Additionally, recent studies have found that the presence of as few as 10\% TCs within a PTC significantly influences patient prognosis, and there was no statistical difference between PTCs with $10-50 \%$ and more than $50 \%$ TCs $(5,6,9)$. The term PTCTCF was used to define those PTCs having the features of TCs but do not reach the cut-off percentage criteria $(6,8)$. Because of these continuing debates, we need to identify an appropriate threshold of TCs to use in the diagnosis of TCVPTC. The purpose of this meta-analysis was to investigate the clinicopathological features of PTC-TCF in comparison with TCVPTC and classical PTC to clarify the controversial issue.

\section{Methods}

\section{Search strategy and study identification}

We searched four main electronic databases (PubMed, Scopus, ISI Web of Science and Virtual Health Library) to identify relevant articles using the following search terms: (tall cell OR tall-cell) AND (papillary thyroid) AND (carcinoma OR cancer OR tumor OR tumour OR neoplasm). We included publications published before July 2018. Our study generally followed the recommendations of Preferred Reporting Items for Systematic Review and Meta-analysis (PRISMA) statement (10).

\section{Selection criteria and abstract screening}

We imported search results from all libraries into Endnote (Thompson Reuters) and deleted duplicates. Two reviewers independently screened the abstracts using the predetermined selection criteria. We used the following inclusion criteria: (i) studies containing data of at least two of the following groups: TCVPTC (PTC with more than $50 \%$ of TC), PTC-TCF (PTC with less than 50\% of TC) and control group (classical PTC) and (ii) studies with clear criteria for TC and TCVPTC/PTC-TCF. The exclusion criteria were (i) studies lack of data of TCVPTC and PTCTCF, (ii) studies including different variants (e.g., follicular variant) other than classical variant in the control group, (iii) datasets considered as overlapping or duplicated,

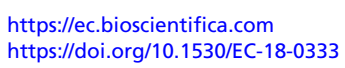

(iv) reviews, (v) case reports and (vi) proceedings papers, posters, theses and books. The two reviewers solved any disagreements in their analyses through discussion and consensus.

\section{Full-text screening and data extraction}

The two reviewers screened the full texts of potential articles and extracted data into a predefined data extraction form. Any disagreements, if present, were solved again by discussion and consensus. The reviewers extracted the following details pertaining to TCVPTC, PTC-TCF and classical PTC: institution, city, country, year of publication, time of operation, criteria for TCVPTC /PTC-TCF, multifocality, extrathyroidal extension, lymph node metastasis, pathological $\mathrm{T}$ factor of the TNM staging system (pT factor), distant metastasis at time of presentation, tumor recurrence or cancer-related mortality.

\section{Risk of bias assessment}

We assessed the methodologic quality of the studies included in our meta-analyses based on the NewcastleOttawa Scale (NOS) for the quality of cohort and casecontrol studies (11). Each cohort and case-control study received a star (maximum nine stars) based on a developed checklist (11). We considered studies awarded at least six stars as moderate-to-high-quality studies and those with a NOS value of fewer than six stars as low-quality studies.

\section{Data analysis}

The Review Manager 5.3 software (Cochrane Collaborative, Oxford, UK) was used for statistical analysis. We calculated pooled estimates of ORs and corresponding 95\% CIs using a random-effect model because this model takes into account within-study heterogeneity and its result is similar to the fixed-effect model when heterogeneity is absent.

We quantified heterogeneity between studies by the $I^{2}$ statistic (12) and classified inconsistency across studies as low $\left(25 \%<I^{2}<50 \%\right)$ and high degrees $\left(I^{2} \geq 50 \%\right) . I^{2} \leq 25 \%$ was considered insignificant and interpreted as meaning that the effect size is comparable across studies. Egger's regression test and funnel plot were used to evaluate the presence of publication bias. We used the MAVIS, version 1.1.2-a R package to analyze the Egger's regression test and funnel plot. A $P$ value of less than 0.05 was considered statistically significant publication bias.

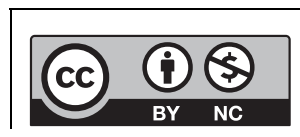

This work is licensed under a Creative Commons Attribution-NonCommercial 4.0 International License. 


\section{Results}

We identified 1335 records after searching four electronic databases using the search terms described earlier. Among them, 38 studies met our selection criteria following the title and abstract screening step. After carefully reading full texts of these studies, we excluded 29 studies. Finally, nine studies comprising 3552 classical PTCs, 325 PTC-TCFs and 403 TCVPTCs were included for final analysis $(5,6,7,9$, 13, 14, 15, 16, 17) (Fig. 1). The quality of included studies ranged from six to seven stars using the NOS (Table 1).

Among the included studies, the thresholds of TCs for PTC-TCF were inconsistent: two studies selected the cut-off of $30-50 \%(7,13)$ and the remaining five studies used the threshold of $10-50 \%$ to define PTC-TCF $(5,6$, $9,14,17)$. The main characteristics of included studies are shown in Table 1 . We performed comparisons for the following groups: TCVPTC vs PTC-TCF, PTC-TCF vs classical PTC and TCVPTC vs classical PTC.

\section{TCVPTC vs PTC-TCF PTC}

The risks for multifocality, extrathyroidal extension, nodal involvement, pT3-T4, distant metastasis and patient mortality were not statistically different between the two groups (Fig. 2 and Table 2). Data for tumor relapse were insufficient for meta-analysis. Among-study heterogeneity was not present in most of the analyses. In the meta-analysis of multifocality, the significant amount of heterogeneity was completely removed after omitting the Beninato et al. study (5) and the insignificant effect remained unaffected $(\mathrm{OR}=0.76 ; 95 \% \quad \mathrm{CI}=0.48-1.21$;
$\left.I^{2}=0 \%\right)$. A high amount of heterogeneity was also present in the meta-analysis of disease mortality $\left(I^{2}=68 \%\right)$. This amount of heterogeneity was completely disappeared after excluding the Ganly et al. study (13) and the overall estimate increased but still insignificant $(\mathrm{OR}=2.30 ; 95 \%$ $\left.\mathrm{CI}=0.69-7.64 ; I^{2}=0 \%\right)$.

\section{PTC-TCF vs classical PTC}

In the studies by Ito et al. (7) and Dettmer et al. (9), the control group contained other PTC variants which could bias the analyses. Therefore, we did not include these two studies in the meta-analyses concerning the comparison of classical PTC with PTC-TCF and TCVPTC. Our results demonstrated that PTC-TCF was associated with a significantly increased risk for all adverse prognostic factors when compared to classical PTC, except tumor recurrence and patient mortality due to lack of data (Fig. 3 and Table 2). The meta-analyses were consistent among all included studies. Only a small amount of heterogeneity was found in the effect of lymph node metastasis $\left(I^{2}=29 \%\right)$. After omitting the study by Ganly et al. (13), the overall effect still remained significant and the among-study heterogeneity was no longer present $\left(\mathrm{OR}=2.38 ; 95 \% \mathrm{CI}=1.68-3.37 ; I^{2}=0 \%\right)$.

\section{TCVPTC vs classical PTC}

The presence of more than 50\% TC in a given PTC was a prognostic indicator for all adverse factors, including tumor recurrence and patient mortality, as compared with classical PTC (Table 2). A considerable amount

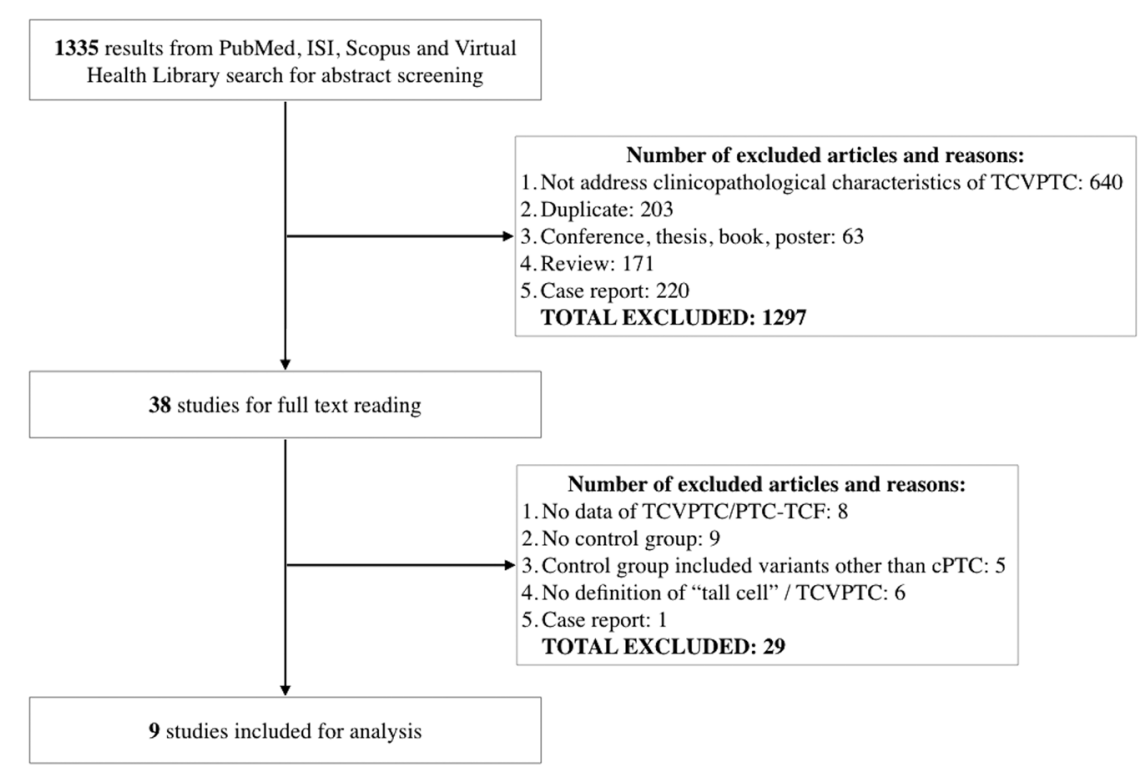

Figure 1

Flowchart of the study selection process. https://ec.bioscientifica.com https://doi.org/10.1530/EC-18-0333
() 2018 The authors Published by Bioscientifica Ltd

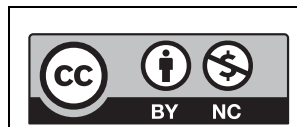

This work is licensed under a Creative Commons Attribution-NonCommercial 4.0 International License. 
Table 1 Characteristics of included studies.

\begin{tabular}{|c|c|c|c|c|c|c|c|c|c|c|}
\hline \multirow[b]{2}{*}{ Study } & \multirow[b]{2}{*}{ Study design } & \multirow{2}{*}{$\begin{array}{l}\text { Criterion of TC } \\
(\mathrm{H}: \mathrm{W} \text { ratio) }\end{array}$} & \multicolumn{2}{|c|}{ Threshold of TC (\%) } & \multicolumn{3}{|c|}{ Number of patients } & \multicolumn{3}{|c|}{$\begin{array}{l}\text { Newcastle- } \\
\text { Ottawa Scale }\end{array}$} \\
\hline & & & TCVPTC & PTC-TCF & TCVPTC & PTC-TCF & CPTC & $\mathrm{S}$ & $\mathrm{C}$ & 0 \\
\hline Beninato 2013 & Retro. cohort & At least 2 & $>50$ & $10-50$ & 26 & 33 & 58 & 3 & 0 & 3 \\
\hline Dettmer 2015 & Retro. cohort & At least 3 & $>50$ & $10-50$ & 21 & 27 & $77 *$ & 3 & 0 & 3 \\
\hline Ganly 2014 & Retro. cohort & At least 2 & $>50$ & $30-50$ & 134 & 31 & 288 & 3 & 0 & 3 \\
\hline Ghossein 2007 & Retro. cohort & At least 3 & $>50$ & NA & 62 & NA & 83 & 3 & 1 & 3 \\
\hline Ito 2017 & Retro. cohort** & At least 3 & $>50$ & $30-50$ & 19 & 51 & $210 *$ & 3 & 0 & 3 \\
\hline Lee 2014 & Retro. Cohort & At least 2 & $>50$ & $10-50$ & 13 & 16 & 202 & 3 & 0 & 3 \\
\hline Oh 2014 & Retro. Cohort & At least 3 & $>50$ & $10-50$ & 95 & 149 & 203 & 3 & 0 & 3 \\
\hline Park 2009 & Retro. Cohort & At least 3 & $>50$ & NA & 11 & NA & 2366 & 3 & 0 & 3 \\
\hline Sampathkumar 2018 & Retro. Cohort & At least 3 & $>50$ & $10-50$ & 22 & 18 & 352 & 3 & 0 & 3 \\
\hline
\end{tabular}

*These data were not included for analysis because the control group contained different variants (e.g., follicular variant) other than classical variant **in this study, the control group was matched with TCVPTC group by age and gender. However, the control group was not included for analysis because it comprised of different variants other than classical variant. There were no matched factors between TCVPTC and PTC-TCF. C, comparability; CPTC, classical PTC; H:W, height to width ratio; NA, not available; O, outcome; PTC-TCF, papillary thyroid carcinoma with tall cell features; S, selection; TC, tall cell; TCVPTC, tall cell variant papillary thyroid carcinoma.

of between-study heterogeneity was present in only a few analyses (lymph node metastasis, pT factor and patient death).

\section{The difference in genetic backgrounds between} TCVPTC, PTC-TCF and classical PTC

Data for $B R A F$ mutation were reported in three studies (6, $9,17)$. The prevalence of $B R A F$ mutation was comparable between TCVPTC and PTC-TCF PTC (OR=0.84; 95\% $\left.\mathrm{CI}=0.18-3.85 ; I^{2}=0 \%\right)$. However, the prevalence of this mutation in TCVPTC and PTC-TCF was significantly higher than that in classical PTC $(\mathrm{OR}=5.43 ; 95 \% \mathrm{CI}=1.78-16.53$; $I^{2}=0 \%$ and $\mathrm{OR}=6.47 ; 95 \% \quad \mathrm{CI}=2.39-17.48 ; \quad I^{2}=0 \%$, respectively). Data of other genetic alterations were insufficient for analysis.

\section{Subgroup analysis}

When we removed the two studies using criterion of $30-50 \%$ TC to define PTC-TCF $(7,13)$, the overall pooled results of PTC-TCFs (10-50\% TCs) did not alter: they showed more aggressive behaviors when compared to classical PTC and did not differ from TCVPTC (Table 3).
A

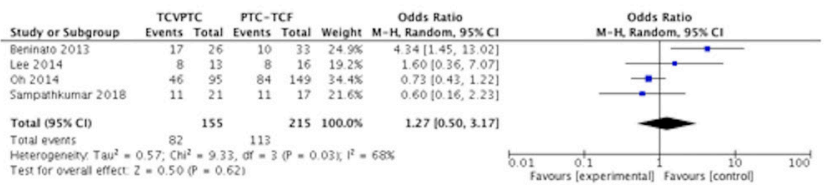

C

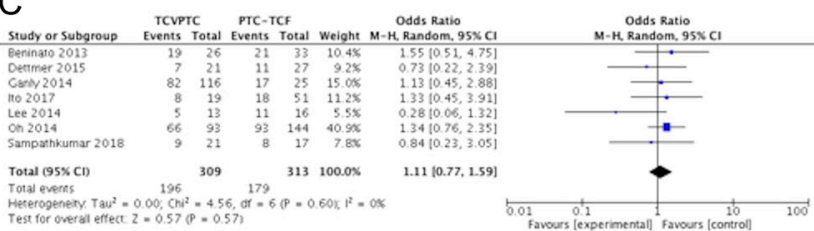

$\mathrm{E}$

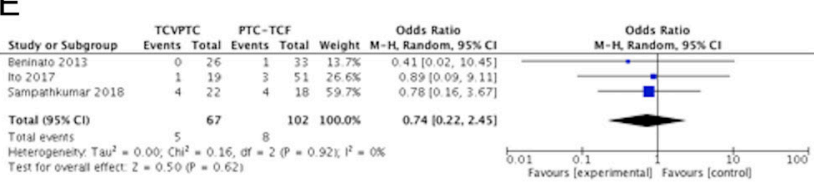

B

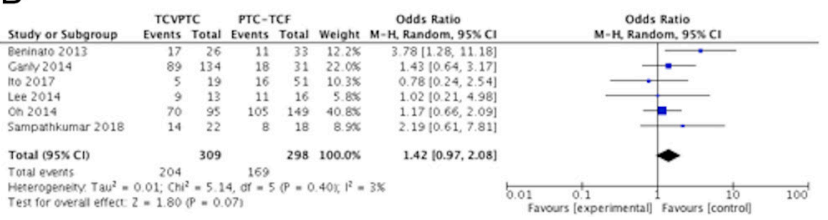

D

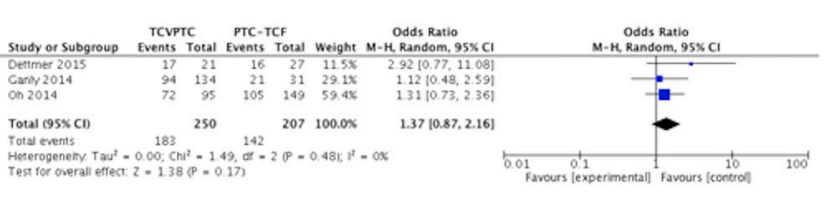

$\mathrm{F}$

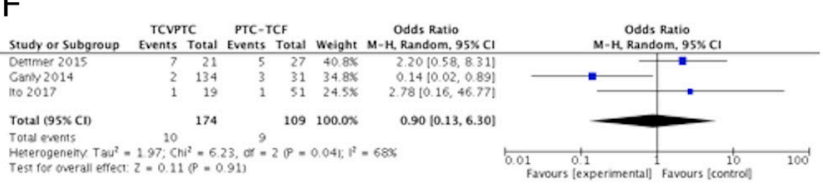

Figure 2

Forest plots examined the clinicopathological significance between TCVPTC and PTC-TCF in multifocality (A), extrathyroidal extension (B), lymph node metastasis (C), pT3 - T4 (D), distant metastasis (E) and patient mortality (F)

https://ec.bioscientifica.com
https://doi.org/10.1530/EC-18-0333 2018 The authors
Published by Bioscientifica Ltd

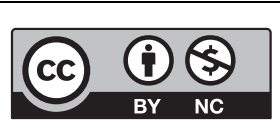

This work is licensed under a Creative Commons Attribution-NonCommercial 4.0 International License. 


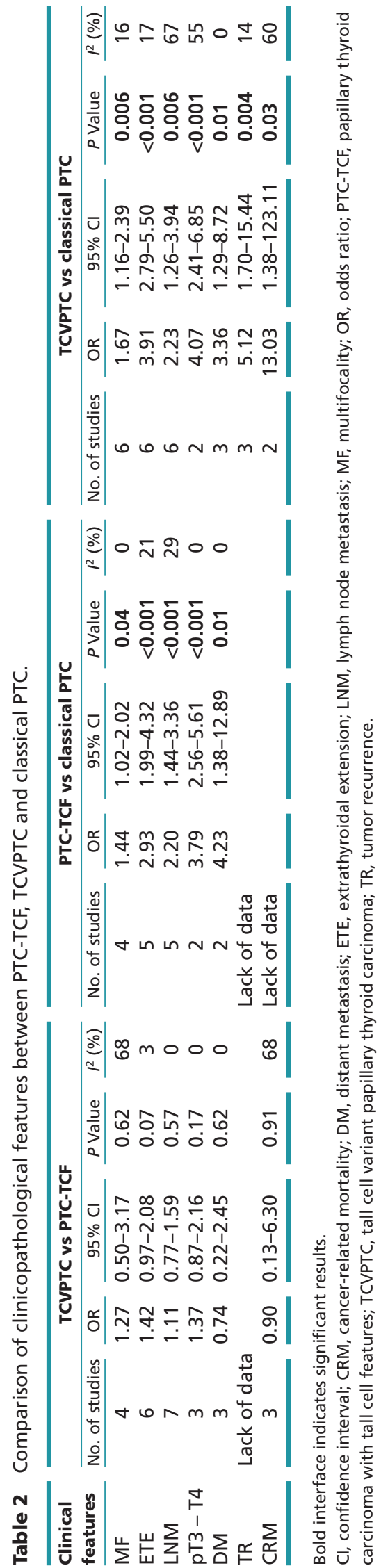

https://ec.bioscientifica.com https://doi.org/10.1530/EC-18-0333

(C) 2018 The authors Published by Bioscientifica Ltd

\section{Publication bias}

To investigate the publication bias, we calculated funnel plots of effects from individual studies. The funnel plots did not indicate a strong publication bias among the set of included studies. Furthermore, tests of asymmetry did not suggest any evidence of publication bias (data not shown).

\section{Discussion}

PTCs are classified into a number of variants and some of them have been considered aggressive variants (e.g., tall cell, diffuse sclerosing, solid, columnar cell, hobnail variant) $(2,18,19,20)$. TCVPTC is a rare variant, but it is of great interest to surgeons and pathologists because it is associated with aggressive behaviors and unfavorable outcomes (21). In the former WHO 2004 classification, the morphological criterion for the diagnosis of a TC was a height at least thrice its width (4). This criterion, however, was modified in the current WHO 2017 classification to a height at least two to three times the cell's width and these cells were required to be present in at least 30\% of all tumor cells to satisfy the diagnosis of TCVPTC (2).

Some published meta-analyses have confirmed the increased aggressiveness of TCVPTCs compared with cPTCs $(22,23)$. However, the definition of TCs and the threshold of these cells for diagnosing TCVPTC were not clearly summarized in these studies. Additionally, a large amount of heterogeneity existed among the analyses in these studies, which may stem from the differences in the diagnostic threshold criteria for TCVPTC between studies. The pooled effect in a meta-analysis is a result of the average effect across all included studies, and if the included studies are too heterogeneous, that average effect is probably not saying anything very useful about what might be observed in a different patient population in another study or another place (12). Recently, a few studies have reported that a PTC with as little as $10 \%$ of TCs behaves aggressively $(5,6,9)$. Because of these reasons, we performed this meta-analysis to answer the question whether the clinical manifestations of PTC-TCF are different from those of TCVPTC and classical PTC.

Our meta-analysis results demonstrated that all clinicopathological features of PTC-TCF were statistically analogous to TCVPTC, except data of disease recurrence due to lack of data. In a previous study, the recurrence rate between these two groups was not statistically different (5). On the other hand, both these two groups showed more aggressive behaviors when compared to classical

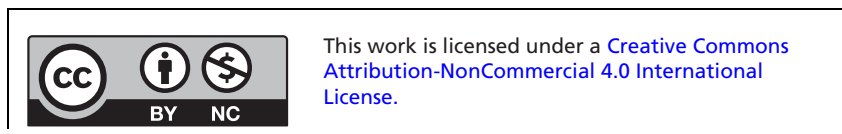




(n)
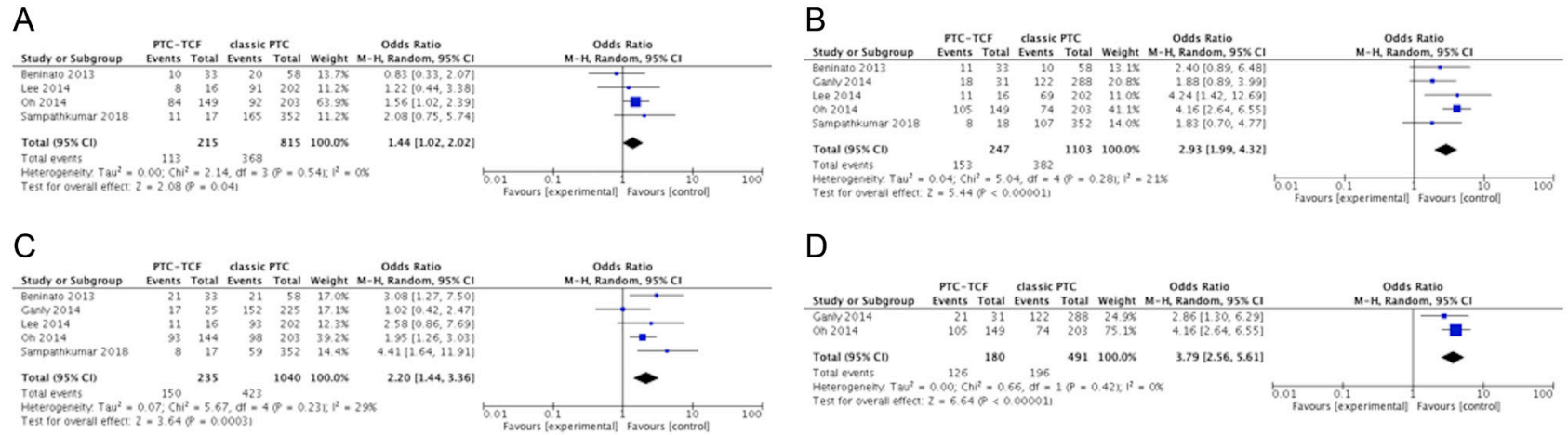

D
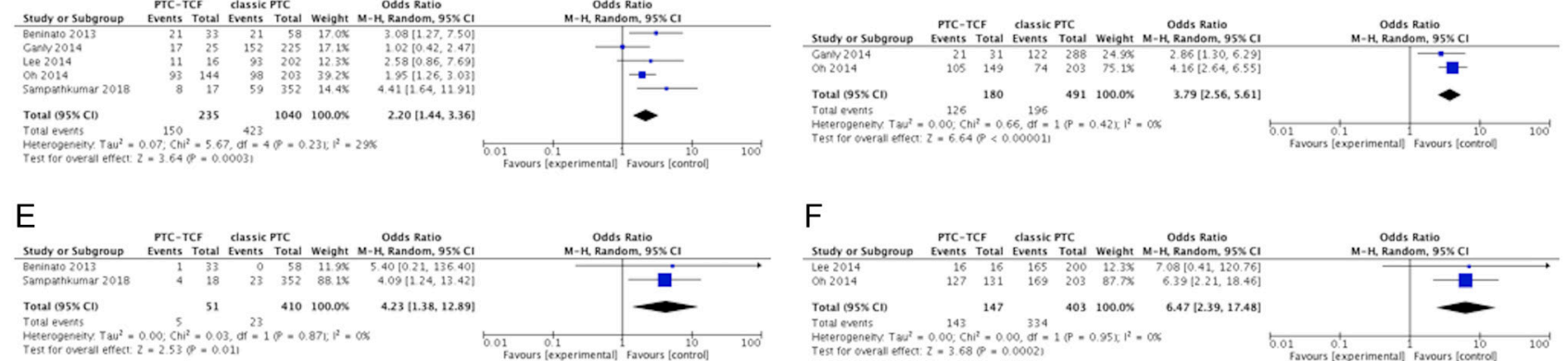

Figure 3

Forest plots examined the clinicopathological significance between PTC-TCF and classical PTC in multifocality (A), extrathyroidal extension (B), lymph node metastasis (C), pT3 - T4 (D), distant metastasis (E) and BRAF mutation (F).

PTC. Additionally, when we limited PTC-TCFs to the group of tumors only comprising of $10-50 \%$ of TCs, these results did not differ from the primary analyses. These findings highlight that even a PTC with as little as 10\% of TCs might have a worse clinical course than classical PTC but does not differ from PTC with more than 50\% of TCs. As a result, we recommend that reporting the percentage of TCs in every case of PTC is important for predicting the aggressiveness of the tumor. Pathologists should carefully examine all tissue blocks of a tumor because the percentage of TCs may not be uniformly present within the sample. Many, if not most, pathologists only examine representative sections. An inaccurate determination of TCs could lower the rate of detection and diagnosis of PTC-TCF/TCVPTC. Currently, there are no guidelines addressing the minimal amount of tissue blocks required to be submitted for histological examination. With the rapid development of computer-assisted techniques and machine learning, there are promising tools that can help clinicians better identify TCs and quantify the number of TCs in a given tumor. However, these tools need to be validated in further studies (24).

In our meta-analysis, it should be noted that no demographic factors (e.g., age, gender) were matched between the TCVPTC, PTC-TCF or classical PTC groups among the included studies. Several studies have pointed out that TCVPTC not only has a worse clinical outcome but is also associated with an older age at presentation (16, $25,26)$. Johnson et al. (27) reported that when adjusted for age, there was no significant difference in the incidence of nodal involvement, extrathyroidal extension and distant metastasis between TCVPTC and classical PTC. In another

Table 3 Comparison of clinicopathological features of PTC-TCF (only limited to studies using cut-off percentage of 10-50\% TCs) with TCVPTC and classical PTC.

\begin{tabular}{|c|c|c|c|c|c|c|c|c|c|c|}
\hline \multirow{2}{*}{$\begin{array}{l}\text { Clinical } \\
\text { features }\end{array}$} & \multicolumn{5}{|c|}{ TCVPTC vs PTC-TCF } & \multicolumn{5}{|c|}{ PTC-TCF vs classical PTC } \\
\hline & No. of studies & OR & $95 \% \mathrm{Cl}$ & $P$ Value & $R^{2}(\%)$ & No. of studies & OR & $95 \% \mathrm{Cl}$ & $P$ Value & $P^{2}(\%)$ \\
\hline MF & 4 & 1.27 & $0.50-3.17$ & 0.62 & 68 & 4 & 1.44 & $1.02-2.02$ & 0.04 & 0 \\
\hline ETE & 4 & 1.67 & $0.93-2.99$ & 0.09 & 26 & 4 & 3.46 & $2.42-4.95$ & $<0.001$ & 0 \\
\hline LNM & 5 & 1.04 & $0.65-1.65$ & 0.87 & 10 & 4 & 2.38 & $1.68-3.37$ & $<0.001$ & 0 \\
\hline pT3 - T4 & 2 & 1.55 & $0.82-2.94$ & 0.18 & 14 & 2 & 4.16 & $2.64-6.55$ & $<0.001$ & 0 \\
\hline DM & 2 & 0.69 & $0.17-2.80$ & 0.6 & 0 & 2 & 4.16 & $1.38-12.89$ & 0.01 & 0 \\
\hline TR & Lack of data & & & & & Lack of data & & & & \\
\hline CRM & 2 & 2.30 & $0.69-7.64$ & 0.18 & 0 & Lack of data & & & & \\
\hline
\end{tabular}

Bold interface indicates significant results.

$\mathrm{Cl}$, confidence interval; CRM, cancer-related mortality; DM, distant metastasis; ETE, extrathyroidal extension; LNM, lymph node metastasis; MF, multifocality; OR, odds ratio; PTC-TCF, papillary thyroid carcinoma with tall cell features; TCVPTC, tall cell variant papillary thyroid carcinoma; TR, tumor recurrence.

$$
\begin{aligned}
& \text { https://ec.bioscientifica.com } \\
& \text { https://doi.org/10.1530/EC-18-0333 } 2018 \text { The authors }
\end{aligned}
$$


case-control study, however, TCVPTC was still associated with an aggressive behavior and a high recurrence rate when controlled for age and gender (28). Therefore, it has to be acknowledged that the clinical significance of TCVPTC is not reached a definitive consensus, and future studies using strict selection/diagnostic criteria and standardized reporting are necessary.

Although there are still ongoing questions as to why TCVPTC exhibit aggressive clinical behaviors, recent progress in the molecular pathogenesis of thyroid cancer may help clarify the biological aggressiveness of this variant. Although the data are limited, our results showed that PTC-TCF has a similar BRAF mutation prevalence to TCVPTC but significantly higher as compared to classical PTC. The more recently discovered TERT promoter mutations were also more prevalent in TCVPTCs than in classical PTCs $(9,29)$. The association of BRAF and TERT promoter mutations with a poor outcome in PTC has been well confirmed in recent meta-analyses $(30,31)$.

This meta-analysis has a few limitations that need to be addressed. All included studies were retrospective cohort studies in nature, and it could lead to selection bias. Another limitation is that follow-up data (tumor recurrence and cancer mortality) were rarely reported among the included studies, especially in the comparison of classical PTC vs PTC-TCF. It could be due to the overall good prognosis of PTC patients. Additional prospective large series with appropriately long follow-up are needed to confirm the prognostic outcomes of the PTC-TCF in comparison with TCVPTC and classical PTC.

In conclusion, PTC-TCF and TCVPTC have similar clinicopathological outcomes and both are associated with a worse prognosis as compared to classical PTC. Our study demonstrated that even a PTC comprising only $10 \%$ of TCs might be associated with a poor clinical outcome. Therefore, it is important to estimate and report the proportions of TC components in PTC even when the proportion is as little as $10 \%$. These findings help clinician better assess patient outcomes, identify the high-risk tumors and tailor appropriate therapeutic decisions.

\section{Declaration of interest}

The authors declare that there is no conflict of interest that could be perceived as prejudicing the impartiality of this review.

\section{Funding}

This work did not receive any specific grant from any funding agency in the public, commercial, or not-for-profit sector.

\section{References}

1 Davies L \& Welch HG. Current thyroid cancer trends in the United States. JAMA Otolaryngology: Head and Neck Surgery 2014140 317-322. (https://doi.org/10.1001/jamaoto.2014.1)

2 Lloyd RV, Osamura RY, Kloppel G \& Rosai J. World Health Organization Classification of Tumours. Pathology and Genetics of Tumours of Endocrine Organs. Lyon: IARC Press, 2017.

3 Hawk WA \& Hazard JB. The many appearances of papillary carcinoma of the thyroid. Cleveland Clinic Quarterly 197643 207-216. (https://doi.org/10.3949/ccjm.43.4.207)

4 De Lellis R, Lloyd R, Heitz P \& Eng C. World Health Organization Classification of Tumours. In Pathology and Genetics of Tumours of Endocrine Organs. Lyon: IARC Press, 2004.

5 Beninato T, Scognamiglio T, Kleiman DA, Uccelli A, Vaca D, Fahey Iii TJ \& Zarnegar R. Ten percent tall cells confer the aggressive features of the tall cell variant of papillary thyroid carcinoma. Surgery 2013154 1331-1336. (https://doi.org/10.1016/j.surg.2013.05.009)

6 Oh WJ, Lee YS, Cho U, Bae JS, Lee S, Kim MH, Lim DJ, Park GS, Lee YS \& Jung CK. Classic papillary thyroid carcinoma with tall cell features and tall cell variant have similar clinicopathologic features. Korean Journal of Pathology 201448 201-208. (https://doi. org/10.4132/KoreanJPathol.2014.48.3.201)

7 Ito Y, Hirokawa M, Miyauchi A, Higashiyama T, Kihara M \& Miya A. Prognostic significance of the proportion of tall cell components in papillary thyroid carcinoma. World Journal of Surgery 201741 742-747. (https://doi.org/10.1007/s00268-016-3784-7)

8 Hernandez-Prera JC, Machado RA, Asa SL, Baloch Z, Faquin WC, Ghossein R, LiVolsi VA, Lloyd RV, Mete O, Nikiforov YE, et al. Pathologic reporting of tall-cell variant of papillary thyroid cancer: have we reached a consensus? Thyroid 201727 1498-1504. (https:// doi.org/10.1089/thy.2017.0280)

9 Dettmer MS, Schmitt A, Steinert H, Capper D, Moch H, Komminoth P \& Perren A. Tall cell papillary thyroid carcinoma: new diagnostic criteria and mutations in BRAF and TERT. EndocrineRelated Cancer 201522 419-429. (https://doi.org/10.1530/ERC-150057)

10 Moher D, Liberati A, Tetzlaff J, Altman DG \& PRISMA Group. Preferred reporting items for systematic reviews and meta-analyses: the PRISMA statement. PLoS Medicine 20096 e1000097. (https://doi. org/10.1371/journal.pmed.1000097)

11 Wells GA, Shea B, O'connell O, Peterson J, Welch V, Losos M \& Tugwell P. The Newcastle-Ottawa Scale (NOS) for assessing the quality of nonrandomised studies in meta-analyses. Ottawa Hospital Research Institute 2011.

12 Higgins JP \& Thompson SG. Quantifying heterogeneity in a metaanalysis. Statistics in Medicine 200221 1539-1558. (https://doi. org/10.1002/sim.1186)

13 Ganly I, Ibrahimpasic T, Rivera M, Nixon I, Palmer F, Patel SG, Tuttle RM, Shah JP \& Ghossein R. Prognostic implications of papillary thyroid carcinoma with tall-cell features. Thyroid 201424 662-670. (https://doi.org/10.1089/thy.2013.0503)

14 Sampathkumar G, Nair V, Menon U, Smitha N, Sundaram S, Kumar H, Pavithran P, Bhavani N, Menon A, Abraham N, et al. A Comparison of clinicopathological characteristics and short-term outcome of papillary thyroid carcinoma with tall cell histology and classic papillary thyroid carcinoma: a single-institution experience. Indian Journal of Endocrinology and Metabolism 201822 405-409. (https://doi.org/10.4103/ijem.IJEM_65_18)

15 Ghossein RA, Leboeuf R, Patel KN, Rivera M, Katabi N, Carlson DL, Tallini G, Shaha A, Singh B \& Tuttle RM. Tall cell variant of papillary thyroid carcinoma without extrathyroid extension: biologic behavior and clinical implications. Thyroid 200717 655-661. (https://doi. org/10.1089/thy.2007.0061)

16 Park JY, Lee JI, Tan AHK, Jang HW, Shin HW, Oh YL, Shin JH, Kim JH, Kim JS, Son YI, et al. Clinical differences between classic papillary

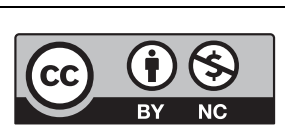

This work is licensed under a Creative Commons Attribution-NonCommercial 4.0 International License. 
thyroid carcinoma and variants. Endocrinology and Metabolism 2009 24 165-173. (https://doi.org/10.3803/jkes.2009.24.3.165)

17 Lee SH, Jung CK, Bae JS, Jung SL, Choi YJ \& Kang CS. Liquid-based cytology improves preoperative diagnostic accuracy of the tall cell variant of papillary thyroid carcinoma. Diagnostic Cytopathology 2014 42 11-17. (https://doi.org/10.1002/dc.23007)

18 Vuong HG, Kondo T, Pham TQ, Oishi N, Mochizuki K, Nakazawa T, Hassell L \& Katoh R. Prognostic significance of diffuse sclerosing variant papillary thyroid carcinoma: a systematic review and meta-analysis. European Journal of Endocrinology 2017176 431-439. (https://doi.org/10.1530/EJE-16-0863)

19 Vuong HG, Odate T, Duong UNP, Mochizuki K, Nakazawa T, Katoh R \& Kondo T. Prognostic importance of solid variant papillary thyroid carcinoma: a systematic review and meta-analysis. Head and Neck 201840 1588-1597. (https://doi.org/10.1002/hed.25123)

20 Haugen BR, Alexander EK, Bible KC, Doherty GM, Mandel SJ, Nikiforov YE, Pacini F, Randolph GW, Sawka AM, Schlumberger M, et al. 2015 American Thyroid Association Management guidelines for adult patients with thyroid nodules and differentiated thyroid cancer: the American Thyroid Association guidelines task force on thyroid nodules and differentiated thyroid cancer. Thyroid 201626 1-133. (https://doi.org/10.1089/thy.2015.0020)

21 LiVolsi VA. Papillary carcinoma tall cell variant (TCV): a review. Endocrine Pathology 201021 12-15. (https://doi.org/10.1007/s12022010-9106-y)

22 Jalisi S, Ainsworth T \& La Valley M. Prognostic outcomes of tall cell variant papillary thyroid cancer: a meta-analysis. Journal of Thyroid Research 20102010 325602. (https://doi. org/10.4061/2010/325602)

23 Liu Z, Zeng W, Chen T, Guo Y, Zhang C, Liu C \& Huang T. A comparison of the clinicopathological features and prognoses of the classical and the tall cell variant of papillary thyroid cancer: a metaanalysis. Oncotarget 20168 6222-6232. (https://doi.org/10.18632/ oncotarget.14055)
24 Kim E, Baloch Z \& Kim C. Computer assisted detection and analysis of tall cell variant papillary thyroid carcinoma in histological images. Medical Imaging 2015: Digital Pathology. Proceedings SPIE, 9420 2015 94200A. (https://doi.org/10.1117/12.2082156)

25 Okuyucu K, Alagoz E, Arslan N, Emer O, Ince S, Deveci S, Ayan A, Taslpnar A, Gunalp B \& Azal O. Clinicopathologic features and prognostic factors of tall cell variant of papillary thyroid carcinoma: comparison with classic variant of papillary thyroid carcinoma. Nuclear Medicine Communications 201536 1021-1025. (https://doi. org/10.1097/MNM.0000000000000360)

26 Moreno Egea A, Rodriguez Gonzalez JM, Sola Perez J, Soria Cogollos T \& Parrilla Paricio P. Prognostic value of the tall cell variety of papillary cancer of the thyroid. European Journal of Surgical Oncology 199319 517-521.

27 Johnson TL, Lloyd RV, Thompson NW, Beierwaltes WH \& Sisson JC. Prognostic implications of the tall cell variant of papillary thyroid carcinoma. American Journal of Surgical Pathology 198812 22-27. (https://doi.org/10.1097/00000478-198801000-00003)

28 Ruter A, Dreifus J, Jones M, Nishiyama R, Lennquist S, Hay ID, Shaha AR, Thompson NW \& Clark OH. Overexpression of p53 in tall cell variants of papillary thyroid carcinoma. Surgery $1996 \mathbf{1 2 0}$ 1046-1050. (https://doi.org/10.1016/S0039-6060(96)80053-5)

29 Gandolfi G, Ragazzi M, Frasoldati A, Piana S, Ciarrocchi A \& Sancisi V. TERT promoter mutations are associated with distant metastases in papillary thyroid carcinoma. European Journal of Endocrinology 2015 172 403-413. (https://doi.org/10.1530/EJE-14-0837)

30 Vuong HG, Duong UNP, Altibi AMA, Ngo HTT, Pham TQ, Tran HM, Gandolfi G \& Hassell L. A meta-analysis of prognostic roles of molecular markers in papillary thyroid carcinoma. Endocrine Connections 20176 R8-R17. (https://doi.org/10.1530/EC-17-0010)

31 Vuong HG, Altibi AMA, Duong UNP \& Hassell L. Prognostic implication of BRAF and TERT promoter mutation combination in papillary thyroid carcinoma-A meta-analysis. Clinical Endocrinology 201787 411-417. (https://doi.org/10.1111/cen.13413)

Received in final form 19 September 2018

Accepted 5 October 2018

Accepted Preprint published online 5 October 2018

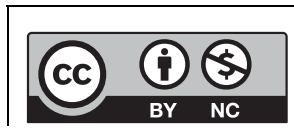

This work is licensed under a Creative Commons Attribution-NonCommercial 4.0 International License. 